\title{
Poly(arylene ether ketone)s composed of a 1,8-diaroylenenaphthalene moiety: a non-coplanarly accumulated aromatic-ring repeating unit
}

\author{
Akiko Okamoto, Daichi Hijikata, Natsumi Sakai and Noriyuki Yonezawa \\ Poly(arylene ether ketone)s composed of a 1,8-diaroylenenaphthalene moiety, which is a non-coplanar accumulated aromatic- \\ ring unit, were successfully synthesized through the nucleophilic aromatic substitution polycondensation of 1,8-bis \\ (4-fluorobenzoyl)-2,7-dimethoxynaphthalene with several arene diols under mild conditions. The polymers show high glass \\ transition temperatures $\left(T_{\mathrm{g}}\right)$, poor solubility and good film-forming ability through heat casting. \\ Polymer Journal (2013) 45, 277-280; doi:10.1038/pj.2012.135; published online 11 July 2012
}

Keywords: congested spatial organization; 1,8-diaroylenenaphthalene; non-coplanarly accumulated aromatic-rings; nucleophilic aromatic substitution polycondensation; poly(arylene ether ketone)s

\section{INTRODUCTION}

Poly(arylene ether ketone)s have received considerable attention because they are among the eminent thermoplastic super-performance engineering polymers that have excellent chemical tolerance. ${ }^{1,2}$ However, the synthetic difficulties resulting from the poor solubility of the intermediate oligomers often restricts their use. During the course of investigations to overcome these problems, the introduction of a crankshaft-shaped moiety has proven to be one of the effective approaches. The twisted accumulated aromatic-ring structures presumably contribute to smooth polymerization without the stable stacking of aligned aromatic rings in the polymer main chains. Such modifications to the chemical structure have also afforded highmolecular-weight wholly aromatic polyketones, that is, poly(arylene ketone)s that are free from ether linkages in the main chain. We have achieved the synthesis of wholly aromatic polyketones ${ }^{3}$ via the electrophilic aromatic aroylation polycondensation using the minute molecular design of acyl-acceptant molecules composed of $2,2^{\prime}$-dioxy-1, $1^{\prime}$-biphenylylene, ${ }^{4} \quad 2,2^{\prime}$-dioxy-1, $1^{\prime}$-binaphthylylene, ${ }^{5}$ and $o$-terphenylylene ${ }^{6}$ moieties.

During the synthetic study of wholly aromatic polyketones, we unexpectedly observed the highly susceptible and selective aroylation at the 1- and 1,8-positions of 2,7-dimethoxynaphthalene., ${ }^{7,8}$ Using $\mathrm{X}$-ray crystal structure analyses, the resulting 1-mono- and 1,8diaroylated naphthalene homologs with various substituents have been shown to contain an accumulated organization of aromatic rings in a non-coplanar arrangement, where the aroyl groups are perpendicularly attached to the naphthalene ring and situated in opposite directions. ${ }^{9,10}$ These non-coplanar accumulation features are distinct from those of the corresponding $\beta$-isomers. ${ }^{11}$ The characteristic congested shapes of these molecules prompted us to trigger the incorporation of the 1,8-diaroyl-2,7-dimethoxynaphthalene moiety into the poly(arylene ether ketone) backbone. When the 1,8-diaroyl2,7-dimethoxynaphthalene unit is incorporated into the polymer molecule, it is expected to have essentially the same topology of non-coplanar accumulated aromatic-rings spatial organization to that of the crystal of the relating diaroylnaphthalene molecule. In addition, the aromatic polymers synthesized via chain elongation at the 1,8 positions of the naphthalene ring core have rarely been reported ${ }^{12}$ in contrast to the analogous aromatic polymers prepared by chain elongation at the 2,6- and 1,5-positions. ${ }^{13-17}$ In this article, we briefly report and discuss the behavior of the polymerization reaction of 1,8 bis(4-fluorobenzoyl)-2,7-dimethoxynaphthalene (1) during nucleophilic aromatic substitution polycondensation and the several curious properties of the resulting polymers in connection with the unique structure of the 1,8-diaroylenenaphthalene unit.

\section{EXPERIMENTAL PROCEDURE}

\section{Measurements}

${ }^{1} \mathrm{H}$ NMR spectra were recorded on a JEOL JNM-AL300 spectrometer $(300 \mathrm{MHz})$ and a JEOL JNM-ECA-500 spectrometer $(500 \mathrm{MHz})$ (JEOL Ltd, Tokyo, Japan). The chemical shifts are expressed in p.p.m. relative to an internal standard of $\mathrm{Me}_{4} \mathrm{Si}(\delta 0.00) .{ }^{13} \mathrm{C}$ NMR spectra were recorded on a JEOL JNM-AL300 spectrometer $(75 \mathrm{MHz})$ and a JEOL JNM-ECA-500 spectrometer $(125 \mathrm{MHz})$. The chemical shifts are expressed in p.p.m. relative to an internal standard of $\mathrm{CDCl}_{3}(\delta 77.0)$. IR spectra were recorded on a JASCO FT/IR-4100 spectrometer (JASCO Corporation, Tokyo, Japan). Elemental analyses were 
performed on a Yanaco CHN CORDER MT-5 analyzer (Yanaco New Science Inc., Kyoto, Japan).

Gel permeation chromatography measurements were performed using a Shodex K-806M column at a flow rate of $0.75 \mathrm{ml} \mathrm{min}^{-1}$ at $40{ }^{\circ} \mathrm{C}$ using $\mathrm{CHCl}_{3}$ as an eluent on a HITACHI L-7100 HPLC pump (Hitachi, Ltd., Tokyo, Japan). The UV absorption was monitored at a wavelength of $254 \mathrm{~nm}$ using a HITACHI L-7405 UV-vis HPLC spectrophotometer. The inherent viscosities $\left(\eta_{\text {inh }}\right)$ were determined in a $\mathrm{NMP}\left(0.3 \mathrm{~g} \mathrm{dl}^{-1}\right)$ solution at $30^{\circ} \mathrm{C}$ using an Ostwald viscometer. The glass transition temperatures $\left(T_{\mathrm{g}} \mathrm{s}\right)$ were determined based on the differential scanning calorimetry (DSC) curves. The DSC curves were recorded on a Rigaku DSC-8230 differential scanning calorimeter (Rigaku Corporation, Tokyo, Japan) at a heating rate of $10 \mathrm{~K} \mathrm{~min}^{-1}$ under nitrogen against the samples that were preheated at the temperature just below the weight-loss-starting temperature followed by quick quenching. The thermal degradation temperatures $\left(T_{\mathrm{d}} \mathrm{s}\right)$ were determined based on a thermogravimetric analysis (TGA) thermogram. The TGA thermogram was recorded on a Rigaku TG-8120 thermogravimeter at a heating rate of $10 \mathrm{~K} \mathrm{~min}^{-1}$.

Synthesis of 1,8-bis(4-fluorobenzoyl)-2,7-dimethoxynaphthalene (1) 2,7-dimethoxynaphthalene ( $5 \mathrm{mmol}, 0.941 \mathrm{~g})$, 4-fluorobenzoic acid (11 mmol, $1.54 \mathrm{~g})$ and $\mathrm{P}_{2} \mathrm{O}_{5}-\mathrm{MsOH}^{18}(22 \mathrm{ml})$ were added to a dried $30 \mathrm{ml}$ one-necked flask. After the reaction mixture had been stirred for $1 \mathrm{~h}$ at $60^{\circ} \mathrm{C}$, it was poured into ice-cold water $(40 \mathrm{ml})$, and the mixture was extracted using $\mathrm{CHCl}_{3}$ $(30 \mathrm{ml} \times 3)$. The combined extracts were washed with aqueous $2 \mathrm{M}$ sodium hydroxide, saturated $\mathrm{NaCl}$ (aq) and dried over anhydrous magnesium sulfate. The solvent was removed under reduced pressure to yield powdery product 1 (quant.).

1,8-bis(4-fluorobenzoyl)-2,7-dimethoxynaphthalene (1). ${ }^{1} \mathrm{H} \mathrm{NMR} \delta(300 \mathrm{MHz}$, $\left.\mathrm{CDCl}_{3}\right): 3.69(6 \mathrm{H}, \mathrm{s}), 7.02(4 \mathrm{H}, \mathrm{dd}, J=8.6 \mathrm{~Hz}), 7.21(2 \mathrm{H}, \mathrm{d}, J=9.3 \mathrm{~Hz})$, $7.71(4 \mathrm{H}, \mathrm{dd}, J=8.2,5.5 \mathrm{~Hz}), 7.95(2 \mathrm{H}, \mathrm{d}, J=9.3 \mathrm{~Hz})$ p.p.m.; ${ }^{13} \mathrm{C}$ NMR $\delta$ $\left(75 \mathrm{MHz}, \mathrm{CDCl}_{3}\right): 56.28,111.12,115.06\left(\mathrm{~d}, J_{\mathrm{C}-\mathrm{F}}=21 \mathrm{~Hz}\right), 125.46,129.75$, $131.51, \quad 131.64, \quad 132.25, \quad 135.18, \quad 156.24,165.49 \quad\left(d, \quad J_{\mathrm{C}-\mathrm{F}}=254 \mathrm{~Hz}\right)$, 195.38 p.p.m.; IR (KBr) 1663,1613,1596, 1567, 1512, 1504, $1270 \mathrm{~cm}^{-1}$; melting point $=196^{\circ} \mathrm{C} ; \mathrm{C}_{26} \mathrm{H}_{18} \mathrm{O}_{4} \mathrm{~F}_{2}$ anal. calcd. for $\mathrm{C}, 72.22 \%$; $\mathrm{H}, 4.20 \%$. Found C, $72.05 \%$; H, $4.20 \%$.

Typical procedure for the nucleophilic aromatic substitution polymerization of monomer 1 using diol 2a

1,8-Bis(4-fluorobenzoyl)-2,7-dimethoxynaphthalene (1, $0.2 \mathrm{mmol}, 86.5 \mathrm{mg})$, diol 2a $(0.2 \mathrm{mmol}, 45.6 \mathrm{mg})$, potassium carbonate $(1.0 \mathrm{mmol}, 138 \mathrm{mg})$, and freshly distilled DMAc $(0.25 \mathrm{ml})$ were placed into a $10 \mathrm{ml}$ one-necked flask that was equipped with a condenser. After the reaction mixture had been stirred at $150^{\circ} \mathrm{C}$ for $48 \mathrm{~h}$, it was poured into methanol $(20 \mathrm{ml})$ to separate the pale yellow precipitate. The precipitate was collected by filtration with suction and dried in vacuo at $80^{\circ} \mathrm{C}$ for $8 \mathrm{~h}$ to yield a pale yellow powder of poly(ether ketone) 3a.

Other reactions were performed using essentially the same procedure as described above.

Poly(ether ketone) $3 a . \quad{ }^{1} \mathrm{H}$ NMR $\delta\left(500 \mathrm{MHz}, \mathrm{CDCl}_{3}\right): 1.65(6 \mathrm{H}, \mathrm{s}), 3.67(6 \mathrm{H}$, s), $6.81(4 \mathrm{H}, \mathrm{brs}), 6.96(4 \mathrm{H}, \mathrm{brs}), 7.11-7.23(6 \mathrm{H}, \mathrm{m}), 7.61(4 \mathrm{H}, \mathrm{brs}), 7.88(4 \mathrm{H}$, brs) p.p.m.; ${ }^{13} \mathrm{C}$ NMR $\delta\left(125 \mathrm{MHz}, \mathrm{CDCl}_{3}\right): 31.10,42.39,111.29,113.43$, $116.68,119.90,121.64,125.53,128.31,131.52,132.02,133.47,146.74,153.38$, 156.16, 161.77, 195.22 p.p.m.; IR (KBr): 1668, 1609, 1592, 1497, 1237, $1269 \mathrm{~cm}^{-1} ; \mathrm{C}_{41} \mathrm{H}_{32} \mathrm{O}_{6}$ anal. calcd. for $\mathrm{C}, 79.34 \% ; \mathrm{H}, 5.20 \%$. Found $\mathrm{C}$, $77.56 \% ; \mathrm{H}, 5.16 \%$

Poly(ether ketone) $3 \boldsymbol{b} . \quad{ }^{1} \mathrm{H}$ NMR $\delta\left(500 \mathrm{MHz}, \mathrm{CDCl}_{3}\right): 3.68(6 \mathrm{H}, \mathrm{s}), 6.84(4 \mathrm{H}$, brs), $6.92-7.08$ ( $8 \mathrm{H}, \mathrm{m}), 7.17$ (2H, brs), 7.62 (4H, brs), 7.89 (2H, brs) p.p.m.; ${ }^{13} \mathrm{C}$ NMR $\delta\left(125 \mathrm{MHz}, \mathrm{CDCl}_{3}\right): 56.59,111.29,116.35,120.14,121.55,121.95$, $125.57,129.61,131.57,132.08,133.54,150.97,154.00,156.18,161.98$, 195.26 p.p.m.; $\mathrm{IR}(\mathrm{KBr}): 1664,1595,1488,1219 \mathrm{~cm}^{-1} ; \mathrm{C}_{38} \mathrm{H}_{26} \mathrm{O}_{7}$ anal. calcd. for C, $76.76 \% ; \mathrm{H}, 4.41 \%$; found $\mathrm{C}, 74.87 \%$; $\mathrm{H}, 4.61 \%$.

Poly(ether ketone) $3 c . \quad{ }^{1} \mathrm{H}$ NMR $\delta\left(500 \mathrm{MHz}, \mathrm{CDCl}_{3}\right): 3.72(6 \mathrm{H}, \mathrm{s}), 6.96(4 \mathrm{H}$, brs), 7.12-7.20 (6H, m), 7.71 (4H, brs), 7.79 (4H, brs) 7.93 (2H, brs) p.p.m.;
${ }^{13} \mathrm{C}$ NMR $\delta\left(125 \mathrm{MHz}, \mathrm{CDCl}_{3}\right): 56.54,111.26,113.68,118.26,118.85,121.15$, $125.58,129.65,131.61,132.39,133.23,134.77,156.29,159.94,163.23,194.27$, 195.53 p.p.m.; IR (KBr): 1661, 1589, 1497, $1238 \mathrm{~cm}^{-1} ; \mathrm{C}_{39} \mathrm{H}_{26} \mathrm{O}_{7}$ anal. calcd. for $\mathrm{C}, 77.22 \%$; $\mathrm{H}, 4.32 \%$; found $\mathrm{C}, 75.21 \%$; $\mathrm{H}, 4.54 \%$.

Poly(ether ketone) $3 d . \quad{ }^{1} \mathrm{H}$ NMR $\delta\left(500 \mathrm{MHz}, \mathrm{CDCl}_{3}\right): 3.69(6 \mathrm{H}, \mathrm{s}), 6.85(4 \mathrm{H}$, brs), 7.09 (4H, brs), 7.18 (2H, brs), 7.65 (4H, brs), 7.91 (2H, brs) p.p.m.; ${ }^{13} \mathrm{C}$ NMR $\delta\left(125 \mathrm{MHz}, \mathrm{CDCl}_{3}\right): 56.57,111.28,116.54,121.50,121.92,125.58$ $129.62,131.54,132.08,133.69,151.98,156.18,161.73,195.27$ p.p.m.; IR (KBr): $1666,1597,1493,1226 \mathrm{~cm}^{-1} ; \mathrm{C}_{32} \mathrm{H}_{22} \mathrm{O}_{6}$ anal. calcd. for C, $76.48 \%$; $\mathrm{H}, 4.41 \%$; found $\mathrm{C}, 76.08 \% ; \mathrm{H}, 4.39 \%$.

Poly(ether ketone) $3 e . \quad{ }^{1} \mathrm{H}$ NMR $\delta\left(300 \mathrm{MHz}, \mathrm{CDCl}_{3}\right): 3.68(6 \mathrm{H}, \mathrm{s}), 6.81-7.02$ $(4 \mathrm{H}, \mathrm{m}), 7.17$ (4H, brs), 7.30 ( $2 \mathrm{H}, \mathrm{brs}), 7.59-7.73$ (4H, m), 7.81 (2H, brs), 7.90 (2H, brs) p.p.m.; ${ }^{13} \mathrm{C}$ NMR $\delta\left(125 \mathrm{MHz}, \mathrm{CDCl}_{3}\right): 56.56,111.29,115.12,115.76$, $117.13,119.86,121.48,125.58,128.00,130.09,131.56,132.12,133.85,135.44$, 154.12, 156.23, 161.31, 195.32 p.p.m.; IR (KBr): 1666, 1634, 1594, 1510, 1498, $1228,1268 \mathrm{~cm}^{-1} ; \mathrm{C}_{36} \mathrm{H}_{24} \mathrm{O}_{6}$ anal. calcd. for C, $78.25 \%$; $\mathrm{H}, 4.38 \%$; found $\mathrm{C}$, $76.92 \% ; \mathrm{H}, 4.58 \%$.

\section{RESULTS AND DISCUSSION}

The bis(fluorobenzoyl)naphthalene monomer, 1,8-bis(4-fluorobenzoyl)-2,7-dimethoxynaphthalene (1), was prepared by the $\mathrm{P}_{2} \mathrm{O}_{5}$ $\mathrm{MsOH}$-mediated direct condensation of 2,7-dimethoxynaphthalene with 4-fluorobenzoic acid according to the previous study (see Supplementary Charts $\mathrm{S} 1-\mathrm{S} 3$ show ${ }^{1} \mathrm{H}$ and ${ }^{13} \mathrm{C}$ NMR spectra of monomer 1). ${ }^{7}$ Based on the X-ray crystal structure analysis, the two aroyl groups of the bis(4-fluorobenzoyl)naphthalene monomer $\mathbf{1}$ are asymmetrically bent (Figure 1; Supplementary Figure S1 shows the X-ray crystal structure with the detailed crystal information). ${ }^{19}$ The interplanar angles between the naphthalene ring and the two benzene ring planes of monomer 1 are $66.88(7)^{\circ}$ and $88.09(6)^{\circ}$, respectively. To our best knowledge,,10,20,21 the 1,8-diaroylated naphthalene molecules that have been reported in this study have larger interplanar angles than other homologous molecules, for example, 1,8-diaroylnaphthalene without 2,7-methoxy groups. ${ }^{22}$ These results indicate that the steric environment around the two carbonyl groups in monomer $\mathbf{1}$ is highly congested.

Table 1 presents the results of the nucleophilic aromatic substitution polymerization of bis(4-fluorobenzoyl)naphthalene monomer 1

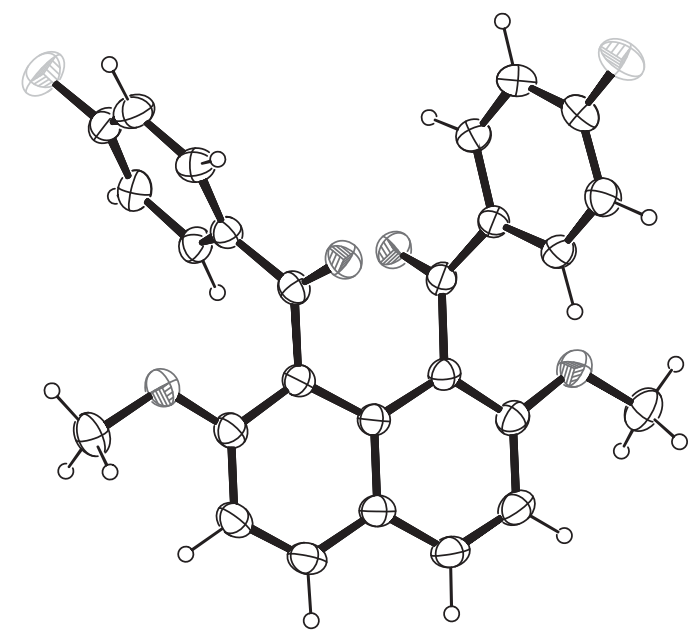

Figure 1 X-ray crystal structure of 1,8-diaroylnaphthalene 1 . A full color version of this figure is available at Polymer Journal online. 
Table 1 Nucleophilic aromatic substitution polycondensation of 1,8-diaroylnaphthalene 1 with diol $2^{\mathrm{a}}$

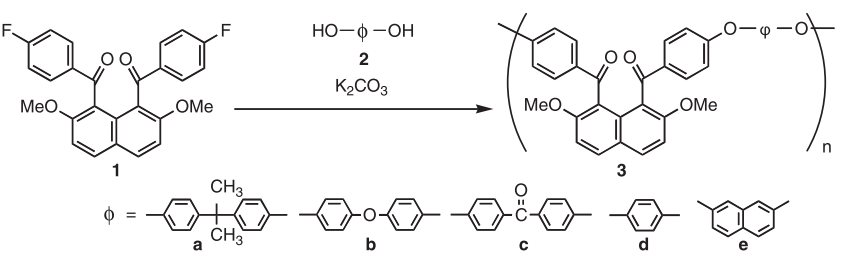

\begin{tabular}{|c|c|c|c|c|c|c|c|c|c|}
\hline Entry & Diol & Solvent & $(m l)$ & $\begin{array}{c}\text { Tempe- } \\
\text { rature } \\
\left({ }^{\circ} \mathrm{C}\right)\end{array}$ & $\begin{array}{l}\text { Time } \\
\text { (h) }\end{array}$ & Product & $\begin{array}{c}\text { Yield } \\
(\%)\end{array}$ & $\begin{array}{c}\eta_{\text {inh }} \\
\left(d l g^{-1}\right)^{\mathrm{b}}\end{array}$ & $\begin{array}{c}\text { Film- } \\
\text { forming } \\
\text { abilityc }\end{array}$ \\
\hline 1 & $2 a$ & DMF & 0.5 & 150 & 24 & $3 a$ & 95 & 0.15 & + \\
\hline 2 & $2 a$ & DMF & 0.25 & 150 & 24 & $3 a$ & 92 & 0.16 & + \\
\hline 3 & $2 a$ & DMF & 0.25 & 150 & 48 & $3 a$ & 95 & 0.18 & + \\
\hline 4 & $2 a$ & NMP & 0.25 & 170 & 6 & $3 a$ & 91 & 0.13 & + \\
\hline 5 & $2 a$ & DMAc & 1.0 & 150 & 24 & $3 a$ & 79 & 0.15 & + \\
\hline 6 & $2 a$ & DMAC & 0.5 & 150 & 24 & $3 a$ & 86 & 0.2 & + \\
\hline 7 & $2 a$ & DMAc & 0.25 & 150 & 24 & $3 a$ & 93 & $(0.49)^{d}$ & ++ \\
\hline 8 & $2 a$ & DMAc & 0.25 & 150 & 48 & $3 a$ & 97 & $n d^{e}$ & ++ \\
\hline 9 & $2 b$ & DMAc & 0.25 & 150 & 48 & $3 b$ & 94 & $n d^{e}$ & ++ \\
\hline 10 & $2 c$ & DMAc & 0.25 & 150 & 48 & $3 c$ & 97 & $n d^{e}$ & + \\
\hline 11 & $2 d$ & DMAc & 0.25 & 150 & 48 & $3 d$ & 100 & $n d^{e}$ & + \\
\hline 12 & $2 e$ & DMAc & 0.25 & 150 & 48 & $3 e$ & 94 & $n d^{e}$ & + \\
\hline
\end{tabular}

Reaction conditions: 1,8-bis(4-fluorobenzoyl)-2,7-dimethoxynaphthalene (1, 0.2 mmol), diol 2 $(0.2 \mathrm{mmol}), \mathrm{K}_{2} \mathrm{CO}_{3}(1.0 \mathrm{mmol})$, solvent $(0.25 \mathrm{ml})$, under $\mathrm{N}_{2}$ atmosphere.

betermined in a NMP solution $\left(0.3 \mathrm{gdl}^{-1}\right)$ at $30^{\circ} \mathrm{C}$

'Film quality: + + Flexible; + Brittle.

dSoluble parts in NMP.

ensoluble in NMP and conc. $\mathrm{H}_{2} \mathrm{SO}_{4}$

Table 2 Numbers of polymerization estimated by ${ }^{1} \mathrm{H}$ NMR spectra and molecular weights calibrated by GPC of poly(ether ketone)s $3^{a}$

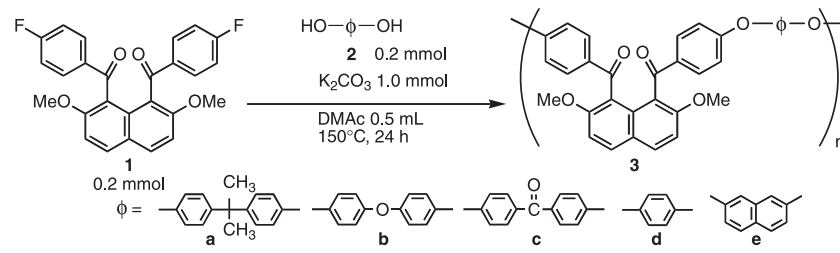

\begin{tabular}{lccccc} 
Entry & Diol & Product & Yield (\%) & $\mathrm{n}^{\mathrm{b}}$ & $\mathrm{M}_{n}{ }^{\mathrm{c}}$ \\
\hline 1 & 2a & 3a & 86 & 32 & 3600 \\
2 & 2b & 3b & 95 & $28-29$ & 5500 \\
3 & 2c & 3c & 86 & 10 & 2100 \\
4 & 2d & 3d & 70 & $40-41$ & 4600 \\
5 & 2e & 3e & 89 & 19 & 2000 \\
\hline
\end{tabular}

Abbreviation: GPC, Gel permeation chromatography.

Reaction conditions: 1,8-bis(4-fluorobenzoyl)-2,7-dimethoxynaphthalene (1,0.2 mmol), diol 2 $(0.2 \mathrm{mmol}), \mathrm{K}_{2} \mathrm{CO}_{3}(1.0 \mathrm{mmol}), \mathrm{DMAc}(0.5 \mathrm{ml}), 150^{\circ} \mathrm{C}, 24 \mathrm{~h}$, under $\mathrm{N}_{2}$ atmosphere.

${ }^{\mathrm{b}}$ Calculated on the basis of ${ }^{1} \mathrm{H}$ NMR spectrum.

'Calibrated on the basis of GPC curve (column: Shodex K-806M. eluent: $\mathrm{CHCl}_{3}$. UV detector: $254 \mathrm{~nm})$.

Table 3 Thermal properties of poly(ether ketone)s $3^{a}$

\begin{tabular}{lccc} 
Entry & Polymer & $\mathrm{T}_{g}\left({ }^{\circ} \mathrm{C}\right)^{\mathrm{a}}$ & $\mathrm{T}_{d 10}\left({ }^{\circ} \mathrm{C}\right)^{\mathrm{b}}$ \\
\hline 1 & 3a & 206 & 366 \\
2 & 3b & 206 & 382 \\
3 & 3c & 213 & 373 \\
4 & 3d & 235 & 401 \\
5 & 3e & 226 & 391 \\
\hline aDetermined on the basis of differential scanning calorimetry curves.
\end{tabular}

bemperature where a $10 \mathrm{wt} \%$ loss was observed in thermogravimetric analysis thermogram.

with bisphenol A (2a) performed in aprotic polar solvents of DMF, NMP and DMAc. In DMF, the polymerization proceeded slowly (Entry 1). Decreasing the volume of DMF and elongating the reaction time slightly accelerated the chain elongation reaction (Entries 2 and 3). In NMP, the polymerization was retarded, even at rather high reaction temperatures (Entry 4). However, the use of smaller amounts of DMAc achieved smooth polymerization (Entries 5,6 and 7 ). In $0.25 \mathrm{ml}$ of DMAc against $0.2 \mathrm{mmol}$ of bis(4fluorobenzoyl)naphthalene monomer $\mathbf{1}$, the reaction solution gradually became viscous, and gelatinous curds were finally formed within $1.5 \mathrm{~h}$ (Entries 7 and 8). After reprecipitation, the precipitated mass of polymer 3a was demonstrated to be insoluble not only in organic solvents but also in conc. $\mathrm{H}_{2} \mathrm{SO}_{4}$ (Entry 8). Polymer 3, which was obtained in Entry 7, was partially soluble in chloroform. The molecular weights of the soluble parts were estimated at approximately $10000(n=16)$ from the ${ }^{1} \mathrm{H}$ NMR spectra. However, the insoluble parts easily yielded a transparent flexible film by heat casting. These results led us to conjecture that the chain elongation reaction proceeded satisfactorily and yielded an insoluble highmolecular-weight polymer. Therefore, diols $\mathbf{2} \mathbf{b}-\mathbf{e}$ were employed as monomers with bis(4-fluorobenzoyl)naphthalene monomer 1 under similar reaction conditions of Entry 8 (Entries 9-12). The corresponding polymerization proceeded smoothly. The products also showed poor solubility in organic solvents and good film-forming ability by heat casting.
Table 2 presents the results of polymerization of bis(4-fluorobenzoyl)naphthalene monomer 1 with several diols 2 performed under gentle reaction conditions, in $0.5 \mathrm{ml}$ of DMAc at $150^{\circ} \mathrm{C}$ for $24 \mathrm{~h}$. The products are easily soluble in $\mathrm{CHCl}_{3}$ (see Supplementary Charts S4-18 show ${ }^{1} \mathrm{H}$ and ${ }^{13} \mathrm{C}$ NMR spectra of the resulting polymers). The numbers of polymerization $(n)$ are determined from the ${ }^{1} \mathrm{H}$ NMR spectra (The ${ }^{1} \mathrm{H}$ NMR spectra are available from Supplementary Information) and calibrated by gel permeation chromatography. The $n$ values that were calibrated by gel permeation chromatography are smaller than those estimated from the ${ }^{1} \mathrm{H}$ NMR spectra. This apparently contradictory observation indicates that the products give small exclusion volumes in $\mathrm{CHCl}_{3}$, although they have large molecular weights. This result can be explained because the polymer chains are tightly folded by the 1,8-diaroylenenaphthalene units. In other words, the structures of 1,8-diaroylenenaphthalene units provide a greater influence to the spatial organization of the polymer than that of the diol units.

Table 3 summarizes the $T_{\mathrm{g}} \mathrm{s}$ and $T_{\mathrm{d}} \mathrm{s}$ of the poly(ether ketone)s 3 determined using DSC and TG, respectively. The $T_{\mathrm{g}} \mathrm{s}$ rise in the order of poly(ether ketone)s $\mathbf{3} \mathbf{a}, \mathbf{3} \mathbf{b}<\mathbf{3} \mathbf{c}<\mathbf{3} \mathbf{e}<\mathbf{3 d}$. In addition, the $T_{\mathrm{d}} \mathrm{s}$ rise in the order of the poly(ether ketone)s $\mathbf{3} \mathbf{a}<\mathbf{3} \mathbf{c}<\mathbf{3 b}<\mathbf{3} \mathbf{e}<\mathbf{3 d}$. The difference in the $T_{\mathrm{g}} \mathrm{s}$ is relatively small. The $T_{\mathrm{g}} \mathrm{s}$ are presumably governed by the restricted rotation of the two adjacent aroylene moieties in the 1,8-diaroylenenaphthalene unit. Flexible diol units such as $\mathbf{2} \mathbf{a}$ and $\mathbf{2} \mathbf{b}$ might permit unrestricted rotation of the bonds. 
The $T_{\mathrm{d}}$ s likely depend on the structure of the diol units. The $\mathrm{sp}^{3}$ carbon in the polymer main chain might lower the $T_{\mathrm{d}}$.

The polymerization behavior and the solubility/thermal elasticity properties of the aromatic poly(ether ketone)s are well explained based on the structural features of the non-coplanar accumulated aromatic-ring repeating units. The polymerization likely proceeds with the folding of the resulting polymer chains at the 1,8-diaroylenenaphthalene moieties. The benzene rings in the poly(ether ketone)s (3) are coagulated to give accumulation of the mass of the benzene rings such as polystyrene. The concentration of the randomly assembled benzene rings in the poly(ether ketone) (3) and polystyrene might be almost equal. However, the mobility of the polymer chain coagulation in the poly(ether ketone)s (3) at room temperature is far less than that of polystyrene. During the solution polymerization of monomer 1, the solvated solvent molecules might be imperfectly squeezed out from the polymer chains until the formation of the less mobile mass of the yielded polyketone (3) finally results in the appearance of gelatinous curds. The solvation of the polymer chain of the polyketone (3) should be slow to present low solubility after the complete desolvation by reprecipitation. However, the good heat-cast film-forming ability of the polyketone (3) is interpreted as follows: Heating of the polymer solid should make the restricted spatial organization of the polymer loosen slightly by rotation of the bonds that are connected to the carbonyl group of the two adjacent aroyl groups in the 1,8-diaroylenenaphthalene moiety, which enables the polymer mass to behave as mobile chains of benzene rings, just as in polystyrene melt.

\section{CONCLUSIONS}

The nucleophilic aromatic polycondensation of bis(4-fluorobenzoyl)naphthalene monomer $\mathbf{1}$, which is a non-coplanar accumulated aromatic-ring molecule, with bisphenols 2 has been successfully achieved in aprotic polar solvents under mild reaction conditions, yielding sufficient amounts of a gelatinoid solid. The solid masses of poly(ether ketone)s 3 obtained via reprecipitation show poor solubility in organic solvents and high film-forming ability through heat casting.

\section{ACKNOWLEDGEMENTS}

This work was partially supported by The Ogasawara Foundation for the Promotion of Science and Engineering, Tokyo, Japan.
1 Attwood, T. E., Dawson, P. C., Freeman, J. L., Hoy, L. R. J., Rose, J. B. \& Stanliland, P. A Synthesis and properties of polyaryletherketones. Polymer 22, 1096-1103 (1981).

2 Hergenrother, P. M., Jensen, B. J. \& Havens, S. Poly(arylene ethers). Polymer 29, 358-369 (1988)

3 Yonezawa, N. \& Okamoto, A. Synthesis of wholly aromatic polyketones. Polym. J. 41 899-928 (2009).

4 Yonezawa, N., Miyata, S., Nakamura, T., Mori, S., Ueha, Y. \& Katakai, R. Synthesis of wholly aromatic polyketones using 2,2'-dimethoxybiphenyl as the acyl-acceptant monomer. Macromolecules 26, 5262-5263 (1993).

5 Maeyama, K., Maeda, S., Saito, H. \& Yonezawa, N. Synthesis of wholly aromatic polyketones containing optically active macrocycles. Polym. J. 39, 342-346 (2007).

6 Maeyama, K., Ohe, T., Nakamura, H. \& Yonezawa, N. Successful synthesis of fully aromatic polyketones via nickel complex-mediated aromatic coupling polymerization of bis(chlorobenzoylated) o-terphenyls. Polym. J. 35, 290-292 (2003).

7 Okamoto, A. \& Yonezawa, N. Reversible ArS $_{E}$ aroylation of naphthalene derivative. Chem. Lett. 38, 914-915 (2009).

8 Okamoto, A., Mitsui, R., Oike, H. \& Yonezawa, N. Lewis acid-mediated ArS E $_{\text {aroylation }}$ of naphthalene derivative: distinct second aroylation behavior of $\alpha$-naphthyl ketone. Chem. Lett. 40, 1283-1284 (2011).

9 Nakaema, K., Watanabe, S., Okamoto, A., Noguchi, K. \& Yonezawa, N. 1,8-Dibenzoyl2,7-dimethoxynaphthalene. Acta Cryst. E64, 0807 (2008).

10 Muto, T., Kato, Y., Nagasawa, A., Okamoto, A. \& Yonezawa, N. [2,7-Dimethoxy-8-(4 methylbenzoyl)-1-naphthyl](4-methylphenyl)methanone. Acta Cryst. E66, o2752 (2010)

11 Kato, Y., Takeuchi, R., Muto, T., Okamoto, A. \& Yonezawa, N. (3,6-Dimethoxynaphthalen-2-yl)(phenyl)methanone. Acta Cryst. E67, 0668 (2011).

12 Wang, Z. Y. \& Guen, A. L. Synthesis and properties of poly(arylene ether)s containing 1,8-dibenzoylnaphthalene units. Macromolecules 28, 3728-3732 (1995).

13 Ohno, M., Takata, T. \& Endo, T. Synthesis of a novel naphthalene-based poly(arylene ether ketone) with high solubility and thermal stability. Macromolecules 27, 3447-3447 (1994).

14 Bottino, F. A., Pasquale, G. D., Leonardi, N. \& Pollicino, A. Synthesis and characterization of new poly(arylene ether)s based on dihydroxynaphthalene isomers. Polymer 3914, 3199 (1998)

15 Nehls, S. B., Füldner, S., Preis, E., Farrell, T. \& Scherf, U. Microwave-assisted synthesis of 1,5- and 2,6-linked naphthylene-based ladder polymers. Macromolecules 383, 687-694 (2005).

16 Lynch, P. J., O’Neill, L., Bradley, D., Byrne, H. J. \& McNamara, M. Systematic study on the effects of naphthalene and anthracene substitution on the properties of PPV derivative conjugated systems. Macromolecules 4022, 7895-7901 (2007).

17 Shao, K., Zhu, J., Zhao, C., Li, X., Cui, Z., Zhang, Y., Li, H., Xu, D., Zhang, G., Fu, T., Wu, J., Na, H. \& Xing, W. Naphthalene-based poly(arylene ether ketone) copolymers containing sulfobutyl pendant groups for proton exchange membranes. J. Polym. Sci. A Polym. Chem. 47, 5772-5783 (2009).

18 Eaton, P., Carlson, G. R. \& Lee, J. T. Phosphorus pentoxide-methane sulfonic acid Convenient alternative to polyphosphoric acid. J. Org. Chem. 38, 4071-4073 (1973).

19 Watanabe, S., Nagasawa, A., Okamoto, A., Noguchi, K. \& Yonezawa, N. (2,7Dimethoxynaphthalene-1,8-diyl)bis(4-fluorobenzoyl)dimethanone. Acta Cryst. E66, 0329 (2010).

20 Sasagawa, K., Muto, T., Okamoto, A., Oike, H. \& Yonezawa, N. [8-(4-Butoxybenzoyl)2,7-dimethoxynaphthalen-1-yl](4-butoxyphenyl)methanone. Acta Cryst. E67, 03354 (2011).

21 Muto, T., Sasagawa, K., Okamoto, A., Oike, H. \& Yonezawa, N. (3,5-Dimethylphenyl)[8(3,5-dimethylbenzoyl)-2,7-dimethoxynaphthalen-1-yl]methanone. Acta Cryst. E68, 01200 (2012).

22 Cohen, S., Thirumalaikumar, M., Pogodin, S. \& Agranat, I. Peri interactions in naphthalene diketones: a preference for $(\mathrm{Z}, \mathrm{Z})$ conformations. Struct. Chem. 154, 339-346 (2004).

Supplementary Information accompanies the paper on Polymer Journal website (http://www.nature.com/pj) 